\title{
Breast Carcinoma During Pregnancy
}

\section{International Recommendations from An Expert Meeting}

0 ne of the recommendations from an expert meeting ${ }^{1}$ regarding breast carcinoma treatment during pregnancy was that radiation therapy should be delayed until after delivery. However, we believe the authors have overestimated the risks of radiation therapy.

The risks of irradiation have been reviewed previously by the International Commission on Radiological Protection. ${ }^{2,3}$ In general, the expected effects are malformations, a decrease in intelligence, mental retardation (deterministic effects), and cancer induction. For deterministic effects, threshold doses of $\geq 0.2$ gray (Gy) have been found. An estimate of the lifetime risk of radiation-induced fatal cancer at $0.01 \mathrm{~Gy}$ is approximately $0.06 \%$.

Maternal breast irradiation in the first 8 weeks of organogenesis will expose the fetus to $0.05-0.15$ Gy (the reference dose is $50 \mathrm{~Gy}$ ). Toward the end of pregnancy, the fetus lies closer to the radiation field and could receive $>1$ Gy for the same treatment course. ${ }^{4}$ However, the fetal dose due to leakage radiation from the tube head of the linear accelerator and scatter from collimator and blocks can be reduced with a factor 2 to 4 by proper shielding.

Therefore, in the majority of cases, the radiation dose can be kept below the threshold dose for deterministic effects. The risk of radiation-induced cancer is low, and is negligible with a lifetime risk, without irradiation, of approximately 1 in 3 .

A review of successful radiation therapy for breast cancer (as well as Hodgkin disease) with supplemental shielding during pregnancy was published recently. ${ }^{5}$

In summary, the recommendation not to irradiate a pregnant patient until after birth is not tenable. Pregnancy is not a contraindication to radiotherapy in patients with breast cancer and other cancers that develop away from the pelvis.

\section{REFERENCES}

1. Loibl S, von Minckwitz G, Gwyn K, et al. Breast carcinoma during pregnancy: international recommendations from an expert meeting. Cancer. 2006;106: 237-246.

2. International Commission on Radiological Protection. Pregnancy and medical radiation. Annals ICRP. 2000;30:iii-viii,1-43.

3. International Commission on Radiological Protection. Biological effects after prenatal irradiation (embryo and fetus). Annals ICRP. 2003;33:5-206.

4. Van der Giessen PH. Measurement of the peripheral dose for the tangential breast treatment technique with Co-60 gamma radiation and high energy Xrays. Radiother Oncol. 1997;42:257-264.

5. Kal HB. Struikmans H. Radiotherapy during pregnancy: fact and fiction. Lancet Oncol. 2005;6:328-333. 
Henk B. Kal, PhD

Department of Radiotherapy

University Medical Center

Utrecht, Netherlands

Henk Struikmans, MD, PhD

Department of Radiotherapy

Medical Center Haaglanden

The Hague, Netherlands

DOl 10.1002/cncr.22062

Published online 6 July 2006 in Wiley InterScience

(www.interscience.wiley.com).

\author{
J.W.-Goethe University \\ Frankfurt am Main, Germany \\ Gunther von Minckwitz, MD \\ Department of Obstetrics and Gynaecology \\ J.W.-Goethe University \\ Frankfurt am Main, Germany; \\ German Breast Group \\ Neu-Isenburg, Germany \\ DOl 10.1002/cncr.22065 \\ Published online 6 July 2006 in Wiley InterScience \\ (www.interscience.wiley.com).
}

\section{Author Reply}

W e agree with Drs. Kal and Struikmans that the risk to the fetus during radiotherapy for supradiaphragmatic disease appears to be minimal, provided special attention is paid to the treatment techniques and that the fetus is adequately shielded. ${ }^{1}$ Otherwise, the fetus could receive $>1$ gray (Gy) of radiation, especially during the third trimes- ter when the fetus lies closer to the radiation field. ${ }^{2}$

To keep the risk to a minimum, the general recommendation is to postpone radiotherapy until after delivery. ${ }^{3}$ However, the need for immediate radiotherapy in patients with breast carcinoma, in whom it is usually postponed until after chemotherapy and surgery have been completed, and those with Hodgkin disease is different.

In any case, this is a moot point because pregnancy lasts 40 weeks and surgery and chemotherapy will be given before radiotherapy.

However, more information regarding treatment recommendations and their acceptance should be compiled in a registry study such as that of the German Breast Group. ${ }^{4}$

\section{REFERENCES}

1. Kal HB, Struikmans H. Radiotherapy during pregnancy: fact and fiction. Lancet Oncol. 2005;6:328-333.

2. Mazonakis M, Varveris H, Damilakis J, et al. Radiation dose to conceptus resulting from tangential breast irradiation. Int J Radiat Oncol Biol Phys. 2003;55:386-391.

3. Loibl S, von Minckwitz G, Gwyn K, et al. Breast cancer during pregnancy: international recommendations from an expert meeting. Cancer. 2006;106:237-246.

4. GBG Forschungs GmbH. GBG-Studie 29: Brustkrebs in der Schwangerschaft [in German]. Available from URL: www. germanbreastgroup.de/pregnancy Accessed May 31, 2006.

Sibylle Loibl, MD

Manfred Kaufmann, MD

Department of Obstetrics and Gynaecology

\section{Distribution of Human} Papillomavirus Types in ThinPrep Papanicolaou Tests Classified According to the Bethesda 2001 Terminology and Correlations with Patient Age and Biopsy Outcomes

$\mathbf{T}$ he sensitivity of the study by Evans et al. is diminished by the detection of Grade III cervical intraepithelial neoplasia despite an initial diagnosis suggesting benign disease. ${ }^{1}$ More beneficial would be a focus on identifying women age $<30$ years who are at high risk. This is particularly important because this group has been demonstrated to be more likely to be infected with the oncogenic haplotypes of the human papillomavirus (HPV) (e.g., HPV-16, HPV-51, and HPV53) believed to be responsible for both cervical and anal malignancies. ${ }^{2}$ Women with cervical HPV infection have a 3-fold increased risk of concurrent anal infection. There is an approximately $30 \%$ genotypespecific concordance in the HPV haplotypes that cause both anal and cervical cancers. ${ }^{3}$ Attempts to reduce the financial costs of evaluating low-risk women are offset by the ability to simultaneously screen for 2 cancers in high-risk women. Young females, many of whom bear other risk factors for HPV infection (regular use of alcohol, multiple sexual partners, a history of chlamydial infection ${ }^{3}$ ) are increasingly becoming infected at both sites, suggesting vaginal and anal intercourse with the same infected partner(s). The focus of the report by Evans et al. ${ }^{1}$ appears misguided and out of touch with the contemporary epidemiologic impact of HPV. A focus on the identification of young females at a higher risk for oncogenic HPV infection with an emphasis on expedient referral would allow for a more meaningful clinical contribution. 


\section{REFERENCES}

1. Evans MF, Adamson CS, Papillo JL, St. John TL, Leiman G, Cooper K. Distribution of human papillomavirus types in ThinPrep Papanicolaou tests classified according to the Bethesda 2001 terminology and correlations with patient age and biopsy outcomes. Cancer. 2006;106:1054-1064.

2. Daling JR, Madeleine MM, Johnson LG, et al. Human papillomavirus, smoking, and sexual practices in the etiology of anal cancer. Cancer. 2004;101:270-280.

3. Hernandez BY, McDuffie K, Zhu X, et al. Anal human papillomavirus infection in women and its relationship with cervical infection. Cancer Epidemiol Biomarkers Prev. 2005;14(11 Pt 1):2550-2556.

4. Daling JR, Weiss NS, Hislop TG, et al. Sexual practices, sexually transmitted diseases, and the incidence of anal cancer. N Engl J Med. 1987;317:973-977.

Awori J. Hayanga, MD Department of General Surgery University of Michigan Health Systems Ann Arbor, Michigan DOI 10.1002/cncr.22048 Published online 13 June 2006 in Wiley InterScience (www.interscience.wiley.com).

\section{Author Reply}

W e thank Dr. Hayanga for the interest in our research, which we maintain is entirely relevant to "contemporary epidemiology." 1 To our knowledge, the study is the first to examine the distribution of human papillomavirus (HPV) types across the Bethesda 2001 diagnostic categories and allows an holistic appreciation of the relationship between HPV type and cytologic diagnosis, biopsy outcome, and age. Currently, high-risk HPV testing by Hybrid Capture $2^{\mathrm{TM}}$ assay (Digene Corporation, Gaithersburg, $\mathrm{MD}$ ) is recommended for patients with atypical squamous cells of undetermined significance (ASCUS). ${ }^{2}$ Our data suggest that high-risk HPV testing, at least by polymerase chain reaction, might also benefit the management of patients with low-grade squamous intraepithelial lesions (LSILs).

Dr. Hayanga's comment that the sensitivity of our study was diminished by the detection of Grade III cervical intraepithelial neoplasia (CIN III) despite an initial diagnosis suggestive of benign disease is unclear; CIN III was not identified in our series after a negative Papanicolaou (Pap) test, but rather was detected only after abnormal cytology, and was re- corded for a small minority of patients diagnosed with ASCUS or LSIL.

Dr. Hayanga's comments regarding anal carcinoma testing are also unclear, because routine screening is reserved for high-risk male and female groups in large dedicated centers. In addition, the management of preneoplastic anal lesions is controversial, problematic, and fraught with the potential for overtreatment. ${ }^{3}$

Any markers that help identify women at risk for high-grade cervical disease are to be welcomed. However, the "behavioral" identifiers Dr. Hayanga appears to suggest would require questionnaires from each (young) patient undergoing a Pap test. Difficulties in organizing the collection and processing of such data aside, it is likely that most patients would be uncomfortable providing details regarding multiple sexual partners, anal intercourse, alcohol usage, infectious diseases, etc. It is important to avoid any sense of stigmatization that might deter women from participation in cervical screening programs. ${ }^{4}$

\section{REFERENCES}

1. Evans MF, Adamson CS, Papillo JL, St. John TL, Leiman G, Cooper K. Distribution of human papillomavirus types in ThinPrep Papanicolaou tests classified according to the Bethesda 2001 terminology and correlations with patient age and biopsy outcomes. Cancer. 2006;106:1054-1064.

2. Solomon D, Schiffman M, Tarone R. ALTS Study group. Comparison of three management strategies for patients with atypical squamous cells of undetermined significance: baseline results from a randomized trial. J Natl Cancer Inst. 2001;93:293-299.

3. Chin-Hong PV, Palefsky JM. Natural history and clinical management of anal human papilloma virus disease in men and women infected with human immunodeficiency virus. Clin Infect Dis. 2002;35:1127-1134.

4. Helmerhorst TJ, Meijer CJ. Cervical cancer should be considered as a rare complication of oncogenic HPV infection rather than a STD. Int J Gynecol Cancer. 2002;12:235-236.

Mark F. Evans, PhD Gladwyn Leiman, MBBCh Kumarasen Cooper, MBChB, DPhil Department of Pathology University of Vermont College of Medicine Burlington, Vermont DOI 10.1002/cncr.22053 Published online 13 June 2006 in Wiley InterScience (www.interscience.wiley.com) 